\title{
Risk factors for interstage death after stage 1 reconstruction of hypoplastic left heart syndrome and variants
}

David A. Hehir, MD, ${ }^{a, b}$ Troy E. Dominguez, MD, ${ }^{b}$ Jean A. Ballweg, MD, ${ }^{b}$ Chitra Ravishankar, MD, ${ }^{a}$ Bradley S. Marino, MD, MPP, MSCE, ${ }^{\mathrm{b}}$ Geoffrey L. Bird, MD, ${ }^{\mathrm{b}}$ Susan C. Nicolson, MD, ${ }^{\mathrm{b}}$ Thomas L. Spray, MD, ${ }^{\mathrm{c}}$ J. William Gaynor, MD, ${ }^{\mathrm{c}}$ and Sarah Tabbutt, MD, PhD

Earn CME credits at http:// cme.ctsnetjournals.org

Supplemental material is available online.
Objective: The risk of death during the interstage period remains high after stage 1 reconstruction for single ventricle lesions, despite improved surgical results. The purpose of this study is to identify risk factors for interstage death and to describe the events leading to interstage death.

Methods: A nested case-control study was conducted of 368 patients who underwent stage 1 reconstruction at a single center between January 1998 and April 2005.

Results: Among the 313 (85\%) hospital survivors, there were 33 (10.5\%) interstage deaths. Cases more frequently presented with intact or restrictive atrial septum ( 9 [27\%] vs $4[4 \%] ; P<.001)$, were older at the time of surgery (5 [2-40] vs 3 [142] days; $P=.005$ ), had more postoperative arrhythmias (12 [36\%] vs 15 [15\%]; $P=.01)$, and a higher incidence of airway or respiratory complications (12 [36\%] vs 19 [19\%]; $P=.04$ ). By multivariate analysis, only intact atrial septum (odds ratio 7.6; 95\% confidence intervals 1.9-29.6; $P=.003$ ) and age at operation greater than 7 days (odds ratio $3.8 ; 95 \%$ confidence intervals $1.3-11.2 ; P=.017$ ) were predictors of interstage death.

Conclusions: The presence of intact atrial septum and older age at the time of surgery are associated with a higher risk of interstage death. In addition, postoperative arrhythmia and airway complications are associated with a higher risk of interstage death in univariate analysis. The results of this study provide a focus for interstage monitoring and risk stratification of these high-risk infants, which may improve overall survival.

From the Division of Cardiology, ${ }^{\text {a }}$ Department of Anesthesiology and Critical Care Medicine, ${ }^{\mathrm{b}}$ and the Division of Cardiothoracic Surgery ${ }^{c}$ at The Children's Hospital of Philadelphia and University of Pennsylvania School of Medicine, Philadelphia, Pa.

Received for publication June 13, 2007; revisions received Nov 21, 2007; accepted for publication Dec 18, 2007.

Address for reprints: David A. Hehir, MD, Children's Hospital of Philadelphia, Divisions of Cardiology and Critical Care Medicine, 34th St and Civic Center Blvd., Philadelphia, PA 19104 (E-mail: hehir@ email.chop.edu).

J Thorac Cardiovasc Surg 2008;136:94-9 $0022-5223 / \$ 34.00$

Copyright $\odot 2008$ by The American Association for Thoracic Surgery

doi:10.1016/j.jtcvs.2007.12.012
$\mathrm{H}$ ypoplastic left heart syndrome (HLHS) and its variants present unique management challenges to the cardiac intensive care team after stage 1 reconstruction (S1R). Equally challenging is the prevention of interstage death (ISD), defined as death after hospital discharge and before admission for a planned stage 2 reconstruction (S2R). Hospital survival after S1R has improved as a result of continued innovation and refinement in surgical technique, earlier diagnosis and referral to tertiary care centers, and advances in perioperative care. ${ }^{1-10}$ As a result, this group of congenital lesions once considered universally fatal in infancy now has a survival after S1R of $77 \%$ to $93 \% .{ }^{11-16}$ However, at most centers ISD rates are unchanged from historical rates of $7 \%$ to $15 \% \cdot{ }^{17-22}$ Therefore, interstage mortality constitutes an increasing percentage of overall mortality in the current era and is attracting increased clinical and research attention.

The reported causes of ISD range from simple intercurrent illnesses to catastrophic shunt thromboses. ${ }^{19,23}$ In attempts to identify those patients at risk for ISD events, past investigators have identified residual anatomic lesions, depressed myocardial function, elevated systemic vascular resistance, arrhythmia, and noncardiac factors such as seizures and feeding dysfunction as significant risk factors. ${ }^{3,12,19-25}$ It is clear that after 


$$
\begin{aligned}
& \text { Abbreviations and Acronyms } \\
& \begin{array}{ll}
\mathrm{CI} & =\text { confidence interval } \\
\text { ISD } & =\text { interstage death } \\
\mathrm{OR} & =\text { odds ratio } \\
\mathrm{S} 1 \mathrm{R}, \mathrm{S} 2 \mathrm{R} & =\text { stage } 1 \text { reconstruction, stage } 2 \text { reconstruction }
\end{array}
\end{aligned}
$$

S1R, many patients with single ventricle physiology have fragile hemodynamics and at times do not tolerate even minor stressors. Therefore, management strategies have focused on creating a more stable circulation through surgical and medical advances as well as identifying and better monitoring those patients at high risk for ISD. The goal of this study is to identify those patients who are at high risk for ISD, with a secondary goal of describing the events leading to ISD.

\section{Patients and Methods Study Design}

We performed a retrospective case-control study including all patients who underwent S1R at the Children's Hospital of Philadelphia from January 1998 to August 2005. The study was approved by the Institutional Review Board (IRB No. 2004-10-2890); informed consent was waived. Hospital medical records, the Cardiac Center database systems, and outpatient cardiology records were reviewed to identify ISD and control patients. For study patients, additional data reviewed included echocardiography reports, cardiac catheterization reports, and operative reports, including extramural reports when appropriate. Outpatient cardiologists were contacted for follow-up information when necessary. For each case, 3 controls were randomly chosen from the cohort of patients who had undergone surgery within the same calendar year as the case and had survived to $\mathrm{S} 2 \mathrm{R}$.

\section{Definitions}

Patients who died before hospital discharge are designated as hospital deaths. Hospital deaths include patients transferred to referring hospitals who died before discharge from those units. For those patients transferred to a referring hospital, the transfer date was used for calculating length of stay. Inoperable patients were those not referred for S2R within 1 year of S1R owing to unsuitability for further palliation. Transplanted patients were those who underwent S1R but subsequently underwent transplantation before S2R. Hospital deaths, inoperable patients, and transplanted patients were excluded from the control group.

\section{Anatomy and Patient-related Factors}

All patients underwent S1R for lesions consisting of a single functional ventricle with obstruction to systemic outflow (Table 1). Anatomic diagnoses were established from echocardiography reports, cardiac catheterization reports, surgical notes, and autopsy reports. In cases of a disputed diagnosis, operative reports and autopsy reports were given precedence. The diagnosis of intact atrial septum was based on echocardiography or catheterization findings of absent atrial communication. Highly restrictive atrial septum was defined as an atrial septal defect measuring less than $2 \mathrm{~mm}$ and a restrictive Doppler flow pattern. ${ }^{26}$
TABLE 1. Preoperative anatomy: Subclass and variants

\begin{tabular}{lccc}
\hline \multicolumn{1}{c}{ Category } & $\begin{array}{c}\text { Cases } \\
(\mathbf{n}=\mathbf{3 3})\end{array}$ & $\begin{array}{c}\text { Controls } \\
(\mathbf{n = 9 9 )}\end{array}$ & $\boldsymbol{P}$ \\
\hline HLHS (all) & $25(76 \%)$ & $64(65 \%)$ & .20 \\
$\quad$ With aortic atresia & $17(52 \%)$ & $44(44 \%)$ & .48 \\
HLHS variants & & & \\
Complex double-outlet right ventricle & 0 & $9(9 \%)$ & .11 \\
Unbalanced atrioventricular canal & $5(15 \%)$ & $9(9 \%)$ & .33 \\
Other* & $3(9 \%)$ & $17(17 \%)$ & .26
\end{tabular}

* Other includes double-inlet left ventricle with transposition of the great arteries (TGA) and systemic outflow obstruction, tricuspid atresia with TGA and systemic outflow obstruction, TGA with inadequate systemic ventricle and systemic outflow obstruction, and critical aortic stenosis/aortic hypoplasia with inadequate systemic ventricle.

\section{Operative Technique}

The standard S1R performed at our institution during the study period consisted of an atrial septectomy, division of the main pulmonary artery with side-to-side anastomosis to the ascending aorta, or homograft patch augmentation of the ascending aorta and aortic arch, with either a modified Blalock-Taussig shunt or a right ventricular-pulmonary artery conduit as the source of pulmonary blood flow. ${ }^{12}$ From 1998 to 2002, the modified Blalock-Taussig shunt was used exclusively, whereas from 2002 to 2005 there was contemporary use of both shunt types. Five surgeons performed S1R during this period. Repair of additional intracardiac lesions was undertaken simultaneously where appropriate. Modified ultrafiltration was routinely used. In the postoperative period, neither delayed sternal closure nor extracorporeal membrane oxygenation was routinely used. The usual postoperative care during this time period included infusions of milrinone, dopamine, and fentanyl, normal ventilation, normothermia, and discontinuation of neuromuscular blockade the first postoperative night.

\section{Data Analysis}

Demographic data, operative factors, and postoperative events were recorded. Continuous variables are presented as mean ( \pm standard deviation) for normally distributed data and median (range) for nonnormally distributed data. Dichotomous variables are presented as count and percent. Categorical data were compared by the Fisher exact test or $\chi^{2}$ test where appropriate. For comparison of continuous variables between cases and controls, a Student $t$ test was used for normally distributed data and a Wilcoxon rank sum test otherwise. An a priori significance level of $\alpha=.05$ was used. Stepwise logistic regression using backward selection was performed to identify independent risk factors found to be significant from univariate analysis. Analysis was performed with STATA 8.0 (STATA Corporation 2003, College Station, Tex).

\section{Main Results}

During the study period, there were 33 (10.5\%) ISDs (Figure E1). Of the original cohort of 368 patients, $263(71 \%)$ went on to S2R, from which the control group was taken.

\section{Risk Factors for ISD}

Preoperative demographic and cardiac features analyzed are shown in Table 2. Patients with an intact or highly restrictive atrial septum 
TABLE 2. Preoperative variables: Demographics and cardiac features

\begin{tabular}{|c|c|c|c|}
\hline Variable & $\begin{array}{c}\text { Cases } \\
(\mathbf{n}=\mathbf{3 3})\end{array}$ & $\begin{array}{l}\text { Controls } \\
(\mathrm{n}=99)\end{array}$ & $\boldsymbol{P}$ \\
\hline Gender ( $\%$ male $)$ & $19(57 \%)$ & $66(67 \%)$ & .35 \\
\hline Birth weight (kg) & $3.0(1.5-4.2)$ & $3.2(1.6-4.5)$ & .43 \\
\hline Gestational age (wk) & $40(30-41)$ & $39(31-41)$ & .28 \\
\hline Age at time of surgery (d) & $5(2-40)$ & $3(1-42)$ & .005 \\
\hline Age at surgery $>7 d$ & $10(30 \%)$ & $10(10 \%)$ & .006 \\
\hline Birth weight $<2.5 \mathrm{~kg}$ & $6(18 \%)$ & $15(15 \%)$ & .68 \\
\hline Born remote to surgical center & $14(42 \%)$ & $50(50 \%)$ & .42 \\
\hline Prenatal diagnosis & $15(45 \%)$ & $61(62 \%)$ & .11 \\
\hline \multicolumn{4}{|c|}{ Syndromes and major malformations } \\
\hline Major noncardiac anomaly & $7(21 \%)$ & $16(16 \%)$ & .5 \\
\hline Heterotaxy syndrome & $3(9 \%)$ & $4(4 \%)$ & .37 \\
\hline \multicolumn{4}{|l|}{ Cardiac variables } \\
\hline Single left ventricle & 0 & $14(14 \%)$ & .02 \\
\hline $\begin{array}{l}\text { Intact or highly restrictive } \\
\text { atrial septum }\end{array}$ & $9(27 \%)$ & $4(4 \%)$ & $<.001$ \\
\hline $\begin{array}{l}\text { Preoperative AV valvular } \\
\text { insufficiency* }\end{array}$ & $7(21 \%)$ & $14(14 \%)$ & .34 \\
\hline
\end{tabular}

$A V$, Atrioventricular. *Preoperative AV valvular insufficiency rated as moderate or greater by echocardiography.

were at significantly higher risk of ISD $(9[27 \%]$ cases vs 4 [4\%] controls; $P<.001)$. A single morphologically left ventricle was protective $(0$ cases vs $14[14 \%]$ controls; $P=.02)$. No other preoperative anatomic or functional cardiac factor was found to be significant. Among the patient demographic preoperative variables analyzed, only age at the time of operation was found to be significant: 5 days $(2-40)$ in cases versus 3 days $(1-42)$ in controls $(P=.005)$.

No difference was found in any operative factor analyzed (Table 3). Of the postoperative factors evaluated (Table 4), airway or respiratory anomalies or respiratory complications were more common in cases (12 cases [36\%] vs 19 controls [19\%]; $P=.04$ ), and postoperative arrhythmias necessitating an intervention were more frequently documented in cases (12 cases [36\%] vs 15 controls $[15 \%] ; P=.01)$. Of the cases with a significant postoperative

\section{TABLE 3. Operative variables}

\begin{tabular}{lccc}
\hline \multicolumn{1}{c}{ Variable } & $\begin{array}{c}\text { Cases } \\
(\mathbf{n = 3 3 )}\end{array}$ & $\begin{array}{c}\text { Controls } \\
(\mathbf{n = 9 9 )}\end{array}$ & $\boldsymbol{P}$ \\
\hline Operative times (mean $\pm \mathrm{SD})$ & & & \\
$\quad$ Cardiopulmonary bypass time (min) & $96 \pm 34$ & $95 \pm 26$ & .85 \\
$\quad$ Circulatory arrest time (min) & $44 \pm 13$ & $46 \pm 16$ & .63 \\
Shunt type: RV-PA & $3(9 \%)$ & $14(14 \%)$ & .45 \\
Delayed sternal closure & $6(18 \%)$ & $14(14 \%)$ & .58 \\
Postoperative ECM0 & $2(6 \%)$ & $1(1 \%)$ & .15 \\
Surgical revision* & $1(3 \%)$ & $6(6 \%)$ & .68 \\
\hline
\end{tabular}

$S D$, Standard deviation $R V-P A$, right ventricle-pulmonary artery conduit; ECMO, extracorporeal membrane oxygenation. Surgical revision, * revision of S1R within the same admission.
TABLE 4. Postoperative variables

\begin{tabular}{|c|c|c|c|}
\hline Variable & $\begin{array}{l}\text { Cases } \\
(n=33)\end{array}$ & $\begin{array}{l}\text { Controls } \\
(\mathrm{n}=99)\end{array}$ & $\boldsymbol{P}$ \\
\hline Postoperative arrhythmia & $12(36 \%)$ & $15(15 \%)$ & .01 \\
\hline Postoperative arrest* & $2(6 \%)$ & $1(1 \%)$ & .15 \\
\hline \multicolumn{4}{|l|}{ Airway and respiratory: } \\
\hline Need for reintubation & $10(30 \%)$ & $17(17 \%)$ & .11 \\
\hline Vocal cord paresis & $4(12 \%)$ & $4(4 \%)$ & .11 \\
\hline Diaphragm paresis & 0 & $3(3 \%)$ & .57 \\
\hline Tracheostomy & $2(6 \%)$ & $2(2 \%)$ & .26 \\
\hline Any airway complication $\dagger$ & $12(36 \%)$ & $19(19 \%)$ & .04 \\
\hline Nasogastric feeding at discharge & $14(42 \%)$ & $49(49 \%)$ & .48 \\
\hline Surgical gastric tube & $5(15 \%)$ & $7(7 \%)$ & .16 \\
\hline Postoperative seizure & $6(18 \%)$ & $9(9 \%)$ & .15 \\
\hline Abnormal MRI & $10(30 \%)$ & $22(22 \%)$ & .35 \\
\hline \multicolumn{4}{|l|}{$\mathrm{ECHO}$ measures at discharge } \\
\hline Ventricular dysfunction $\ddagger$ & 0 & $3(3 \%)$ & .57 \\
\hline Residual coarctation & $1(3 \%)$ & $3(3 \%)$ & 1 \\
\hline AV valvular insufficiency $\S$ & $10(30 \%)$ & $20(20 \%)$ & .23 \\
\hline Neoaortic insufficiency\| & $4(12 \%)$ & $4(4 \%)$ & .11 \\
\hline On oxygen at discharge & $8(24 \%)$ & $15(15 \%)$ & .23 \\
\hline Discharge on $>3$ medications & $20(60 \%)$ & $41(41 \%)$ & .06 \\
\hline
\end{tabular}

$M R I$, Magnetic resonance imaging; $E C H O$, echocardiographic; $A V$, atrioventricular. *Postoperative arrest requiring cardiopulmonary resuscitation including chest compressions. †Any airway complication: need for reintubation or vocal cord paresis or diaphragm paresis or trachesostomy. $\ddagger$ Ventricular dysfunction rated at moderate or greater. $\S A V$ valvular insufficiency rated at moderate or greater. ||Neoaortic insufficiency rated mild or greater.

arrhythmia, 4 had a re-entrant supraventricular tachycardia, 3 junctional ectopic tachycardia, 2 ectopic atrial arrhythmias and frequent atrial ectopy, and 2 ventricular tachycardia. One patient had highgrade heart block that resolved before discharge. Cardiac status at the time of discharge was no different between the groups, as evaluated by echocardiographic features, need for oxygen, and number of medications.

Multivariate logistic regression revealed intact or highly restrictive atrial septum (odds ratio [OR] 7.6; 95\% confidence intervals $[\mathrm{CI}] 1.9-29.6 ; P=.003)$ and age at operation greater than 7 days (OR 3.8; 95\% CI 1.3-11.2; $P=.017$ ) to be independent risk factors for ISD.

\section{Circumstances of ISD}

The circumstances of ISD events are detailed in Table 5. Death occurred at a median of 64 (18-257) days of age. The median time from discharge to ISD was 44 (2-188) days. Fourteen (42\%) ISD patients experienced sudden, unexpected deaths at home. Interestingly, 11 (33\%) patients died during a subsequent hospitalization. Of these, 4 died after a procedure (Nissen fundoplication, gastrostomy tube manipulation, shunt revision, and cardiac catheterization). The remainder were hospitalized with a wide range of diagnoses, including respiratory insufficiency and/or infections (n $=4)$, severe cardiac dysfunction $(n=2)$, and feeding dysfunction $(\mathrm{n}=1)$. In 8 patients, information regarding the ISD event was not obtained. Autopsy results were available for 8 patients (Table E1). 
TABLE 5. Circumstances of interstage death events

\begin{tabular}{|c|c|c|c|c|}
\hline Patient & $\begin{array}{l}\text { Age at } \\
\text { OR (days) }\end{array}$ & $\begin{array}{l}\text { Age at } \\
\text { ISD (days) }\end{array}$ & Circumstances of ISD & Known risk factors at discharge* \\
\hline 1 & 2 & 104 & Unknown & None \\
\hline 2 & 15 & 31 & Observed emesis and arrest in hospital; GER & VCP \\
\hline 3 & 4 & 18 & Sudden death at home; cyanosis on $\mathrm{O}_{2}$ & None \\
\hline 4 & 5 & 165 & Died after G-tube exchange; severe TR & IAS; arrhythmia; failed extubation \\
\hline 5 & 3 & NA & Sudden death at home & IAS; arrhythmia \\
\hline 6 & 5 & 51 & Sudden death at home & None \\
\hline 7 & 2 & 31 & Respiratory arrest; readmitted for CRI & Tracheostomy; failed extubation \\
\hline 8 & 2 & 125 & Unknown & None \\
\hline 9 & 12 & 23 & Unknown & Arrhythmia \\
\hline 10 & 5 & 140 & Readmitted with PHTN; DNR & Arrhythmia; failed extubation \\
\hline 11 & 2 & 49 & ICU arrest; readmitted with severe dysfunction & None \\
\hline 12 & 3 & 115 & Sudden death at home; severe TR & Arrhythmia; failed extubation \\
\hline 13 & 2 & 96 & Sudden death at home; recent $C$. diff admission & VCP; failed extubation \\
\hline 14 & 3 & 73 & Sudden death at home & Failed extubation \\
\hline 15 & 4 & 57 & Sudden death at home & IAS; arrhythmia; failed extubation \\
\hline 16 & 7 & 59 & ICU arrest; RSV; interim stent for IAS & None \\
\hline 17 & 10 & 48 & ICU arrest: aspiration pneumonia & None \\
\hline 18 & 40 & 135 & Sudden death at home; likely BTS occlusion & IAS; arrhythmia \\
\hline 19 & 5 & 62 & Died due to complications from Nissen & None \\
\hline 20 & 6 & 120 & Sudden death at home associated with fever & None \\
\hline 21 & 3 & 78 & $\begin{array}{l}\text { Died after shunt revision. Died during readmission } \\
\text { for shunt revision }\end{array}$ & None \\
\hline 22 & 7 & 38 & Unknown & None \\
\hline 23 & 4 & 27 & Sudden death at home; declining cardiac function & Arrhythmia \\
\hline 24 & 22 & 257 & Unknown & Arrhythmia; tracheostomy \\
\hline 25 & 22 & 104 & Died after complications of catheterization & None \\
\hline 26 & 5 & 64 & Unknown & IAS \\
\hline 27 & 8 & 120 & Sudden death at home; diarrhea, dehydration & IAS; arrhythmia \\
\hline 28 & 13 & 142 & Sudden death at home; progressive cyanosis & VCP \\
\hline 29 & 8 & 62 & Unknown & None \\
\hline 30 & 12 & NA & Sudden death at home & IAS; arrhythmia; failed extubation, VCP \\
\hline 31 & 4 & 71 & Sudden death at home likely related to bacteremia & Arrhythmia; failed extubation \\
\hline 32 & 4 & 59 & Unknown & IAS \\
\hline 33 & 4 & 142 & Readmitted with URI; observed apnea in hospital & None \\
\hline
\end{tabular}

OR, Operation; ISD, interstage death; GER, gastroesophageal reflux disease; $V C P$, vocal cord paresis; G-tube, surgical gastrostomy feeding tube; $T R$, tricuspid regurgitation; IAS, intact or highly restrictive atrial septum; CRI, chronic respiratory insufficiency; PHTN, pulmonary hypertension; DNR, Do Not Resuscitate order; C. diff, Clostridium difficile; BTS, Blalock-Taussig shunt; URI, upper respiratory infection. ${ }^{*}$ Risk factors including: IAS; age at surgery $>7$ days; arrhythmia; airway/respiratory complications (failed extubation, vocal cord paresis, diaphragm paresis, or tracheostomy). ICU = Intensive care unit; RSV = Respiratory syncytial virus.

One patient had a documented shunt thrombosis, and another had evidence of diffuse thrombosis and emboli, but no occlusive thrombus in the shunt was found at the time of autopsy. In 3 patients there was evidence of myocardial ischemia and infarction, 2 of whom had significant involvement of the tricuspid apparatus. One patient had polymicrobial bacteremia, possibly associated with bowel perforation and bacterial translocation. In 2 patients, the autopsy did not suggest any cause of death.

\section{Discussion}

As recent advances have led to improved operative outcomes in HLHS and its variants, we hope this study will advance the development of management strategies to improve interstage outcomes. In this cohort, restriction at the level of the atrial septum and delayed time of surgery were found to be independent risk factors for ISD. In addition, univariate analysis found the occurrence of a perioperative arrhythmia or an airway or respiratory complication more frequently in cases. These modifiable risk factors provide intriguing targets for future interventions in addition to guiding risk stratification for the development of interstage monitoring protocols.

Patients with an intact or highly restrictive atrial septum are at high risk for mortality at every stage of single ventricle palliation, including the interstage period. These patients have evidence of abnormal pulmonary vasculature from birth, with "arterialization" of the pulmonary veins and 
dilation of pulmonary lymphatics. ${ }^{26}$ As a result, they are more likely to have elevated pulmonary arterial pressures and are theoretically more susceptible to perturbations of pulmonary and systemic vascular resistance associated with interstage stressors. Recent research efforts have focused on fetal intervention, using either early surgical or interventional catheterization techniques to relieve the obstruction before the development of pulmonary vascular disease. ${ }^{27}$ Whether these interventions will positively affect outcomes remains to be seen. It is unclear whether the administration of supplemental oxygen or other medications targeting the pulmonary vascular bed in the interstage period would be beneficial in this select patient population.

Delayed surgery in single ventricle lesions may occur as the result of late presentation, prematurity or low birth weight, presentation with multisystem organ dysfunction, and in some centers after primary consideration for transplantation. Past studies have shown that older age at time of presentation and at time of operation results in worse outcomes in this population. ${ }^{21,26,27}$ In this study, we found that patients older than 7 days at the time of operation were more likely to have ISD. In most cases there is no advantage in delaying surgery; however, individual patients have survived delayed palliation, and in specific circumstances it may be necessary to delay S1R. ${ }^{6}$ It is likely that this variable represents a marker for level of illness at presentation in the current cohort: well patients with no organ dysfunction are more likely to go to the operating room promptly and have a favorable operative and postoperative course.

Our finding that perioperative arrhythmia is more commonly identified in ISD patients agrees with previous studies. ${ }^{17,21}$ Of the 12 ISD patients identified with significant postoperative arrhythmia, 9 (27\%) were discharged receiving a medication specifically to treat or prevent arrhythmia. Only 1 patient from the entire cohort had a documented arrhythmia at the time of ISD and received cardioversion in the field for wide complex tachycardia, without return of spontaneous circulation. This patient was not among those known to have a perioperative arrhythmia. Arrhythmia may explain a significant proportion of unexpected ISD but represents a difficult target for retrospective study. Arrhythmia as a cause of death cannot be diagnosed at autopsy, nor is rhythm at the time of arrest always possible to ascertain in the field. Kaltman and associate ${ }^{28}$ prospectively compared indices of heart rate variability in infants who underwent single ventricle palliation to those with 2-ventricle repairs of various congenital lesions. The authors demonstrated a significant reduction in heart rate variability and a higher baseline heart rate during the vulnerable period for ISD in these patients.

The causes of death in this series were varied, and no previously unrecognized residual technical issues were identified on autopsy. In an autopsy series of 122 deaths after S1R from 1980 to 1995, Bartram, Grunenfelder, and Van Praagh $^{23}$ concluded that, in their series, most deaths were attributable to potentially correctable residual technical issues. Data from our institution and other large centers demonstrate that many of these technical issues have been eliminated or substantially improved on in the current era. ${ }^{11-15,21}$ Therefore, causes of ISD that previously constituted a smaller proportion of total post-S1R mortality (eg, arrhythmia, shunt thrombosis, viral infections) have become more prevalent. Fenton and coworkers ${ }^{19}$ described a series of patients with shunt-dependent pulmonary blood flow who had ISD and found that autopsy-proven shunt thrombosis occurred in $33 \%$ of these patients. Other retrospective clinical studies have found the rate of shunt thrombosis to be from $8 \%$ to $16 \%,{ }^{1,3,13}$ whereas in our experience only $6 \%$ of ISDs were associated with possible shunt thrombosis on autopsy. Interestingly, Fenton's group ${ }^{19}$ found no difference in the incidence of ISD or shunt thrombosis in patients taking aspirin and those receiving no anticoagulation. The ideal anticoagulation strategy remains an important area of discussion at every stage of single ventricle palliation.

High systemic afterload may play a significant role in the pathogenesis of unexpected ISD in this population. Recent studies have highlighted the important role of afterload reduction in postoperative care and long-term management. ${ }^{3,8,25}$ In addition, there is mounting evidence that autonomic function is altered after cardiac surgery, ${ }^{28}$ which may further impair the ability of these patients to compensate for wide swings in systemic vascular resistance associated with intercurrent illnesses and other interstage stressors. In this cohort, patients with significant atrioventricular valvular regurgitation or ventricular dysfunction in the postoperative period were frequently prescribed captopril, but oral afterload reduction was not routine.

It is unlikely that a single surgical or medical intervention will significantly improve current ISD rates owing to the heterogeneous nature of ISD events. It may be more effective to focus our attention during the interstage period on identifying those most at risk, increasing and standardizing surveillance, and investigating subtle abnormalities earlier. In a study using an intensive multidisciplinary interstage monitoring program, Ghanayem and associates ${ }^{20}$ demonstrated an improvement in the ISD rate from $15.8 \%$ to $0 \%$ during the study period. At the time of discharge, study patients were provided with a scale, pulse oximeter, and journal wherein weights and saturation levels were recorded daily by parents. Thirteen of 24 patients were found to have a decrease in saturation level or failure to gain weight; these patients underwent S2R at a median of 3.7 months versus 5.2 months for those with the usual interstage course. In our cohort, although a significant number of patients died after rehospitalization, the most common scenario was a sudden unexpected death at home. In roughly half of these cases, either progressive cyanosis or an identifiable preceding minor illness was found. These symptoms, though nonspecific, may be early signs of impending ISD and require greater attention. 


\section{Limitations}

The main limitations of this study relate to its retrospective nature. Data surrounding ISD events and autopsy reports were limited or unavailable for some patients, especially those cared for outside the referral area. During the study period, evaluation of airway or respiratory complications in all patients was not standard. The decision to perform bronchoscopy was at the discretion of the clinician; in general, only those patients who were especially symptomatic were referred for evaluation. Therefore, potentially not all patients with vocal cord paralysis were identified, and it is possible we may have missed more subtle vocal cord disease. In addition, small numbers of patients with specific risk factors limit the predictive power of this analysis.

\section{Conclusions}

ISD remains a significant source of mortality in HLHS and its variants, occurring in $10.5 \%$ of patients surviving to hospital discharge. Patients with an intact or highly restrictive atrial septum and those undergoing S1R at greater than 7 days of life are at significantly higher risk for ISD. In addition, the presence of a postoperative arrhythmia or postoperative airway or respiratory complication is associated with a greater risk of ISD in univariate analysis. The causes of ISD are multiple, and it is unlikely that a single surgical or medical intervention will significantly improve the incidence of ISD. The results of this study provide a foundation for prospective interstage surveillance focused on minimizing ISD and improving overall outcomes in patients with single ventricle.

\section{References}

1. Andrews R, Tulloh R, Sharland G, Simpson J, Rollings S, Baker E, et al. Outcome of staged reconstructive surgery for hypoplastic left heart syndrome following antenatal diagnosis. Arch Dis Child. 2001;85: 474-7.

2. Checchia PA, Larsen R, Sehra R, Daher N, Gundry SR, Razzouk AJ, et al. Effect of a selection and postoperative care protocol on survival of infants with hypoplastic left heart syndrome. Ann Thorac Surg. 2004;77:477-83.

3. De Oliveira NC, Ashburn DA, Khalid F, Burkhart HM, Adatia IT, Holtby HM, et al. Prevention of early sudden circulatory collapse after the Norwood operation. Circulation. 2004;110:II133-8.

4. Mahle WT, Clancy RR, McGaurn SP, Goin JE, Clark BJ. Impact of prenatal diagnosis on survival and early neurologic morbidity in neonates with the hypoplastic left heart syndrome. Pediatrics. 2001;107:1277-82.

5. Norwood WI, Lang P, Hansen DD. Physiologic repair of aortic atresiahypoplastic left heart syndrome. N Engl J Med. 1983;308:23-6.

6. Rossi AF, Sommer RJ, Steinberg LG, Gross RP, Seiden HS, Golinko RJ, et al. Effect of older age on outcome for stage one palliation of hypoplastic left heart syndrome. Am J Cardiol. 1996;77:319-21.

7. Sano S, Ishino K, Kawada M, Arai S, Kasahara S, Asai T, et al. Right ventricle-pulmonary artery shunt in first-stage palliation of hypoplastic left heart syndrome. J Thorac Cardiovasc Surg. 2003;126:504-9.

8. Tweddell JS, Hoffman GM, Fedderly RT, Berger S, Thomas JP Jr, Ghanayem NS, et al. Phenoxybenzamine improves systemic oxygen delivery after the Norwood procedure. Ann Thorac Surg. 1999;67:161-7.
9. Tworetzky W, McElhinney DB, Reddy VM, Brook MM, Hanley FL, Silverman NH. Improved surgical outcome after fetal diagnosis of hypoplastic left heart syndrome. Circulation. 2001;103:1269-73.

10. Ungerleider RM, Shen I, Yeh T, Schultz J, Butler R, Silberbach M, et al. Routine mechanical ventricular assist following the Norwood procedure: improved neurologic outcome and excellent hospital survival. Ann Thorac Surg. 2004;77:18-22.

11. Azakie T, Merklinger SL, McCrindle BW, Van Arsdell GS, Lee KJ, Benson LN, et al. Evolving strategies and improving outcomes of the modified Norwood procedure: a 10-year single-institution experience. Ann Thorac Surg. 2001;72:1349-53.

12. Gaynor JW, Mahle WT, Cohen MI, Ittenbach RF, DeCampli WM, Steven JM, et al. Risk factors for mortality after the Norwood procedure. Eur J Cardiothorac Surg. 2002;22:82-9.

13. Kern JH, Hayes CJ, Michler RE, Gersony WM, Quaegebeur JM. Survival and risk factor analysis for the Norwood procedure for hypoplastic left heart syndrome. Am J Cardiol. 1997;80:170-4.

14. Tabbutt S, Dominguez TE, Ravishankar C, Marino BS, Gruber PJ, Wernovsky G, et al. Outcomes after the stage I reconstruction comparing the right ventricular to pulmonary artery conduit with the modified Blalock Taussig shunt. Ann Thorac Surg. 2005;80:1582-90.

15. Tweddell JS, Hoffman GM, Mussatto KA, Fedderly RT, Berger S, Jaquiss RD, et al. Improved survival of patients undergoing palliation of hypoplastic left heart syndrome: lessons learned from 115 consecutive patients. Circulation. 2002;106(12 Suppl 1):I82-9.

16. Mahle WT, Spray TL, Wernovsky G, Gaynor JW, Clark BJ III. Survival after reconstructive surgery for hypoplastic left heart syndrome: a 15-year experience from a single institution. Circulation. 2000;102:III136-41.

17. Simsic JM, Bradley SM, Stroud MR, Atz AM. Risk factors for interstage death after the Norwood procedure. Pediatr Cardiol. 2005;26:400-3.

18. Azakie A, Martinez D, Sapru A, Fineman J, Teitel D, Karl TR. Impact of right ventricle to pulmonary artery conduit on outcome of the modified Norwood procedure. Ann Thorac Surg. 2004;77:1727-33.

19. Fenton KN, Siewers RD, Rebovich B, Pigula FA. Interim mortality in infants with systemic-to-pulmonary artery shunts. Ann Thorac Surg. 2003;76:152-6.

20. Ghanayem NS, Hoffman GM, Mussatto KA, Cava JR, Frommelt PC, Rudd NA, et al. Home surveillance program prevents interstage mortality after the Norwood procedure. J Thorac Cardiovasc Surg. 2003;126:1367-77.

21. Mahle WT, Spray TL, Gaynor JW, Clark BJ III. Unexpected death after reconstructive surgery for hypoplastic left heart syndrome. Ann Thorac Surg. 2001;71:61-5.

22. Pizarro C, Mroczek T, Malec E, Norwood WI. Right ventricle to pulmonary artery conduit reduces interim mortality after stage 1 Norwood for hypoplastic left heart syndrome. Ann Thorac Surg. 2004;78:1959-63.

23. Bartram U, Grunenfelder J, Van Praagh R. Causes of death after the modified Norwood procedure: a study of 122 postmortem cases. Ann Thorac Surg. 1997;64:1795-802.

24. Abdullah MH, Van Arsdell GS, Hornberger LK, Adatia I. Precoronary stenosis after stage I palliation for hypoplastic left heart syndrome. Ann Thorac Surg. 2000;70:2147-9.

25. Wright GE, Crowley DC, Charpie JR, Ohye RG, Bove EL, Kulik TJ. High systemic vascular resistance and sudden cardiovascular collapse in recovering Norwood patients. Ann Thorac Surg. 2004;77:48-52.

26. Rychik J, Rome JJ, Collins MH, Decampli WM, Spray TL. The hypoplastic left heart syndrome with intact atrial septum: atrial morphology, pulmonary vascular histopathology and outcome. J Am Coll Cardiol. 1999;34:554-60.

27. Vlahos AP, Lock JE, McElhinney DB, van der Velde ME. Hypoplastic left heart syndrome with intact or highly restrictive atrial septum: outcome after neonatal transcatheter atrial septostomy. Circulation. 2004;109:2326-30.

28. Kaltman JR, Hanna BD, Gallagher PR, Gaynor JW, Godinez RI, Tanel RE, et al. Heart rate variability following neonatal heart surgery for complex congenital heart disease. Pacing Clin Electrophysiol. 2006;29:471-8. 


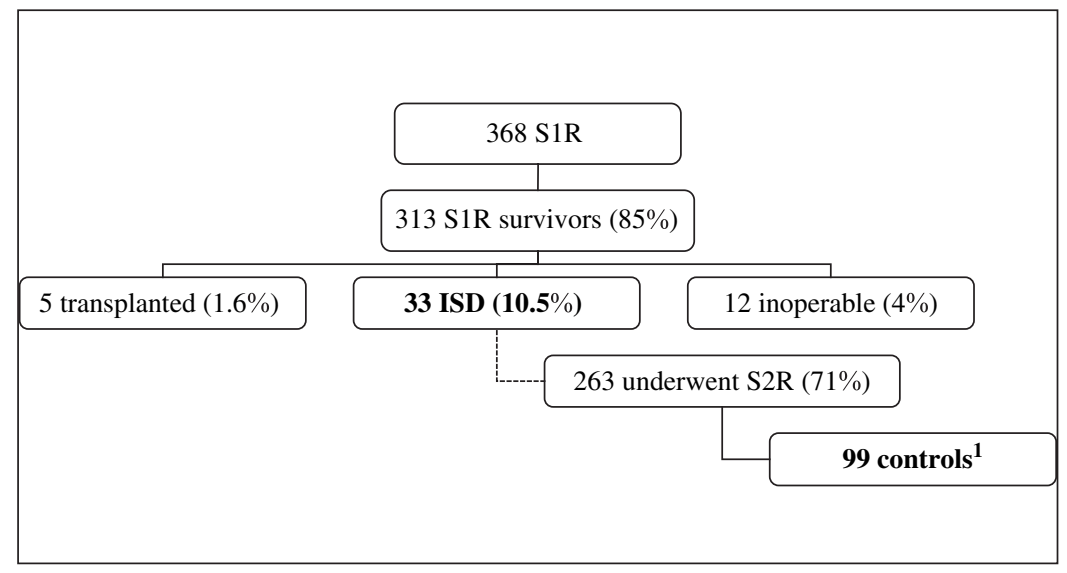

Figure E1. Patient population. Five patients were lost to follow-up after S1R; S1R, Stage 1 reconstruction; ISD, interstage death; $S 2 R$, stage 2 reconstruction. ${ }^{1}$ Controls were randomly selected (3 for each case from within operative year of case) from the cohort of patients surviving to S2R. 
TABLE E1. Results of available autopsies

\begin{tabular}{ll} 
Patient & \multicolumn{1}{c}{ Autopsy results } \\
\hline 2 & Old and new infarctions of the anterior papillary muscle of the tricuspid valve \\
11 & Subendocardial and myocardial infarction and hemorrhage consistent with myocardial infarction \\
15 & Nondiagnostic; right ventricular hypertrophy; small subdural hemorrhage \\
18 & Shunt occlusion with septic thrombus \\
20 & Severe cardiomegaly and right ventricular hypertrophy; residual coarctation $4 \mathrm{~mm}$ \\
21 & Multiple systemic emboli and thromboses including pulmonary and renal \\
27 & Hemorrhage and infarction of papillary muscle; residual coarctation $4 \mathrm{~mm}$ \\
31 & Polymicrobial sepsis; possible bowel infarction \\
\hline
\end{tabular}




\section{APPENDIX E1. Abbreviations and Acronyms}

\begin{tabular}{ll}
\hline AA & Aortic atresia \\
AS & Aortic stenosis \\
AV & Atrioventricular \\
AVC & Atrioventricular canal \\
BTS & Blalock-Taussig shunt \\
C. diff & Clostridium difficile \\
CPB & Cardiopulmonary bypass \\
CRI & Chronic respiratory insufficiency \\
DHCA & Deep hypothermic circulatory arrest \\
DORV & Double-outlet right ventricle \\
DNR & Do Not Resuscitate order \\
DSC & Delayed sternal closure \\
ECMO & Extracorporeal membrane oxygenation \\
GER & Gastroesophageal reflux disease \\
GT & Surgical gastric feeding tube \\
HLHS & Hypoplastic left heart syndrome \\
IAS & Intact or highly restrictive atrial septum \\
ICU & Intensive Care Unit \\
IRB & Institutional review board \\
ISD & Interstage death \\
LV & Left ventricle \\
MA & Mitral atresia \\
mm & Millimeter \\
MRI & Magnetic resonance imaging \\
MS & Mitral stenosis \\
NG & Nasogastric feeding tube \\
PHTN & Pulmonary hypertension \\
RV-PA & Right ventricle to pulmonary artery shunt \\
S1R & Stage 1 reconstruction \\
S2R & Stage 2 reconstruction \\
TGA & Transposition of the great arteries \\
TR & Tricuspid regurgitation \\
URI & Upper respiratory infection \\
VCP & \\
& Vocal cord paresis \\
\hline
\end{tabular}

